\title{
Effects of Intra-Arterial Infusion of Insulin on Forearm Vasoreactivity in Hypertensive Humans
}

\author{
Shinichiro Fujishima, Tsutomu Imaizumi* , Isao Abe, Akira Takeshita*, and Masatoshi Fujishima
}

\begin{abstract}
We previously demonstrated that intra-arterial infusion of insulin attenuates vasoreactivity to phenylephrine and angiotensin II in the forearm of normotensive humans, which suggests that the pressor effects of insulin via sympathetic activation may be offset in peripheral arteries. In the present study, we investigated the effects of insulin on vasoreactivity in hypertensive humans. Seven male patients with essential hypertension (age, 26 \pm 2 yr; blood pressure, 159 $\pm 4 / 103 \pm 4 \mathrm{mmHg}$; mean $\pm S E M$ ) were studied. We measured forearm blood flow by a strain gauge plethysmograph while infusing phenylephrine $(1,4,12 \mathrm{nmol} / \mathrm{min})$ and angiotensin II $(5,10,20 \mathrm{pmol} / \mathrm{min})$ locally into the brachial artery before and during simultaneous intra-arterial infusion of human insulin $(0.15 \mathrm{mU} / \mathrm{kg} / \mathrm{min})$. Forearm vascular resistance was calculated from directly measured arterial pressure and forearm blood flow. Intra-arterial infusion of insulin raised the local plasma insulin level without changing the blood glucose level, basal forearm blood flow, or forearm vascular resistance. Phenylephrine and angiotensin II increased forearm vascular resistance dose-dependently before and during insulin infusion. In contrast to the previous results in normotensive subjects, locally infused insulin did not attenuate vasoconstrictive responses to phenylephrine and angiotensin II in patients with essential hypertension. These results suggest that the balance between the pressor and depressor effects of insulin might be altered in favor of a pressor effect in patients with hypertension. (Hypertens Res 1995; 18: 227-233)
\end{abstract}

Key Words: insulin, hypertension, phenylephrine, angiotensin II, vasoreactivity, humans, plethysmography

Hypertension is associated with insulin-resistance or hyperinsulinemia $(1-7)$. It is postulated that hyperinsulinemia may contribute to hypertension via several different mechanisms (8-14). Although acute hyperinsulinemia activates sympathetic nerve activity $(10,15-17)$, it does not elevate blood pressure in normotensive humans $(17,18)$. To explain this paradox, several investigators reported that insulin has vasodilating effects $(19-21)$, and that insulin decreases vasoreactivity to vasopressor agents (22-25). In particular, we previously demonstrated that intra-arterially infused insulin attenuates the vasoconstricting actions of pressor agents in young normal volunteers (26). Lembo et al. (27) also reported that local hyperinsulinemia reduces the vasoconstrictive response to reflex sympathetic activation in normotensive subjects. Thus in normotensive humans, pressor effects of insulin via sympathetic activation are offset in the peripheral resistance vessels.

Hypertensive patients are insulin-resistant in many aspects $(4,28)$. Furthermore, Baron et al. (8) reported that in patients with hypertension insulin- mediated increases of blood flow in the skeletal muscle were inversely proportional to the basal level of blood pressure, indicating that the vasodilator action of insulin may be decreased in patients with hypertension. Accordingly, we determined the effects of local hyperinsulinemia on basal forearm vascular resistance and on vasoreactivity to intraarterially infused pressor agents in patients with essential hypertension.

\section{Methods}

Subjects

We studied 7 male patients with essential hypertension. They were in their early 20 s except for patient W.J. Hypertension was defined as a systolic or diastolic pressure consistently in excess of $140 \mathrm{mmHg}$ or $90 \mathrm{mmHg}$, respectively, or both, and a diagnosis of hypertension for each patient was made based on several measurements of blood pressure during clinic visits. The patients were hospitalized for evaluation of hypertension. They were in stage I or II of the World Health Organization classification of hyper-

From the Second Department of Internal Medicine, and * Research Institute of Angiocardiology and Cardiovascular Clinic, Faculty of Medicine, Kyushu University, Fukuoka, Japan.

This study was supported by Research Grants for Cardiovascular Disease (3C-5) from the Japanese Ministry of Health and Welfare.

Address for reprints: Shinichiro Fujishima M.D., The Second Department of Internal Medicine, Kyushu University, Maidashi 3-1-1, Higashi-ku, Fukuoka 812, Japan.

Received November 7, 1994; accepted February 13, 1995. 
Table 1. Patient Profiles

\begin{tabular}{|c|c|c|c|c|c|c|c|c|c|c|c|c|}
\hline \multirow{3}{*}{ Patient } & \multirow{3}{*}{$\begin{array}{l}\text { Age } \\
(\mathrm{yr})\end{array}$} & \multirow{3}{*}{$\begin{array}{l}\mathrm{Ht} \\
(\mathrm{cm})\end{array}$} & \multirow{3}{*}{$\begin{array}{l}\text { Wt } \\
(\mathrm{kg})\end{array}$} & \multirow{3}{*}{$\begin{array}{c}\text { BMI } \\
\left(\mathrm{kg} / \mathrm{m}^{2}\right)\end{array}$} & \multirow{3}{*}{$\begin{array}{c}\text { BP } \\
(\mathrm{mmHg})\end{array}$} & \multirow{3}{*}{$\begin{array}{l}\text { Duration } \\
(y r)\end{array}$} & \multicolumn{6}{|c|}{ Response to $75 \mathrm{gOGTT}$} \\
\hline & & & & & & & \multicolumn{3}{|c|}{ Glucose $(\mathrm{mmol} / \mathrm{l})$} & \multicolumn{2}{|c|}{ IRI $(\mu \mathrm{U} / \mathrm{ml})$} & \multirow{2}{*}{$\begin{array}{c}\sum \text { IRI } \\
(\mu \mathrm{U} / \mathrm{ml})\end{array}$} \\
\hline & & & & & & & Before & $60 \mathrm{~min}$ & $120 \mathrm{~min}$ & Before & $120 \mathrm{~min}$ & \\
\hline W.J. & 32 & 173 & 62 & 20.7 & $178 / 126$ & 15 & 5.0 & 12.3 & 12.8 & 1.7 & 112.6 & 114.3 \\
\hline I.Y. & 22 & 174 & 69 & 22.8 & $152 / 96$ & 4 & 4.7 & 9.6 & 4.2 & 4.3 & 9.5 & 13.8 \\
\hline M.Y. & 24 & 169 & 62 & 21.7 & $170 / 112$ & 2 & 4.4 & 5.7 & 6.5 & 4.4 & 53.0 & 57.4 \\
\hline H.K. & 22 & 159 & 74 & 29.3 & $146 / 92$ & 1 & 3.7 & 6.7 & 6.0 & 3.2 & 107.8 & 111.0 \\
\hline E.K. & 35 & 167 & 60 & 21.5 & $160 / 100$ & 9 & 4.0 & 8.3 & 5.7 & 3.2 & 25.7 & 28.9 \\
\hline T.F. & 23 & 160 & 59 & 23.0 & $148 / 90$ & 6 & 5.2 & 5.8 & 5.5 & 8.7 & 52.4 & 61.1 \\
\hline M.T. & 22 & 174 & 94 & 31.0 & $144 / 92$ & 1 & 5.2 & 8.7 & 7.4 & 9.6 & 76.7 & 86.3 \\
\hline
\end{tabular}

$\mathrm{Ht}$, height; Wt, weight; BP, blood pressure; BMI, Body mass index; Duration, duration of hypertension; 75gOGTT, 75-g oral glucose torelance test; IRI, immunoreactive insulin.

tension. Before the present study, no subject was taking medications that could lower blood pressure, and none showed any evidence of secondary hypertension. Table 1 summarizes their clinical profiles. Their blood pressure was $159 \pm 4 / 103 \pm 4 \mathrm{mmHg}$ (means \pm SEM), measured using a mercury sphygmomanometer, on the admission day. Three patients had electrocardiographic or echocardiographic findings suggestive of left ventricular hypertrophy. Two of the seven patients were obese, with a body mass index $>27 \mathrm{~kg} / \mathrm{m}^{2}$. One patient showed a diabetic pattern in response to a 75-g oral glucose torelance test (75gOGTT), but his hemoglobin A1c was $5.5 \%$ (normal range, 4.0-6.0\%). Five of the seven patients showed high levels of plasma insulin (immunoreactive insulin, IRI) in 75gOGTT ( $\Sigma$ IRI, 57.4-114.3 $\mu \mathrm{U} / \mathrm{ml}$ ) compared with the Japanese population (29), suggesting that they had insulin-resistance. Omori et al. (29) reported that the mean $\Sigma$ IRI was $26.5 \pm 0.1 \mu \mathrm{U} / \mathrm{ml}$ in the non-hypertensive Japanese male population ( $n=791$; age, $55 \pm 10 \mathrm{yr}$ ), and $33.4 \pm 0.1 \mu \mathrm{U} / \mathrm{ml}$ in the hypertensive Japanese male population $(n=282$; age, $60 \pm 10 \mathrm{yr})$.

The study protocol was approved by the Human Study Committee of the Research Institute of Angiocardiology and Cardiovascular Clinic. Informed consent was obtained from each subject.

\section{General Procedures}

The study was performed with the subjects in the supine position after an overnight fast. Room temperature was maintained at $25^{\circ} \mathrm{C}$. Under local anesthesia with $2 \%(\mathrm{~W} / \mathrm{V})$ procaine, the left brachial artery was cannulated with a 20 -gauge intravascular over-the-needle (tetrafluoroethylene) polycatheter (Quick-Cath; Travenol Laboratories, Inc., Baxter Healthcare Corp., Deerfield, Ill.), which was used for drug infusion as well as for recording arterial pressure. Arterial pressure was recorded by connecting the arterial line to a pressure transducer (Viggo-Spectramed, Oxnard, Calif.) with a threeway stop cock. The arterial line was kept open by infusing heparinized saline $(0.1 \mathrm{ml} / \mathrm{min})$ when no drug was being infused. To obtain blood samples for the measurement of blood glucose levels and plasma insulin concentrations, an antecubital vein of the ipsilateral arm was cannulated with the same type of cannula as that used for the artery. Heart rate was obtained by counting the pulse rate for a few minutes on arterial pressure recordings.

\section{Measurements of Forearm Blood Flow}

Forearm blood flow was measured with a mercuryin-silastic strain-gauge plethysmograph by a venous occlusion technique $(30,31)$. The strain gauge was placed approximately $5 \mathrm{~cm}$ below the antecubital crease. Forearm blood flow (milliliters per minute per 100 milliliters) was calculated from the rate of increase in forearm volume while venous return from the forearm was prevented by inflating a cuff at the upper arm. The pressure in the venous occlusion cuff at the upper arm was $40 \mathrm{mmHg}$. Circulation to the hand was arrested by inflating a cuff around the wrist to a suprasystolic pressure (about $200 \mathrm{mmHg}$ ). The wrist cuff was inflated before the determination of forearm blood flow and continuously throughout the measurements. Forearm vascular resistance was calculated by dividing the mean blood pressure (diastolic blood pressure plus one-third of the pulse pressure in millimeters of mercury) by the forearm blood flow. These values are expressed as arbitrary units throughout this report. An average of four flow measurements made at 15 -second intervals, calculated by two authors independently, was used for analysis.

\section{Forearm Vascular Responses to Drugs}

After the placement of cannulas and a strain-gauge plethysmograph, at least 15 minutes were allowed for subjects to become accustomed to the study conditions before the experiments were begun. We examined responses to intra-arterial infusion of phenylephrine $(n=7)$ and angiotensin II $(n=7)$, administered at graded doses before and during intra-arterial infusion of insulin. First, we examined forearm responses to intra-arterial infusions of phenylephrine $(1,4,12 \mathrm{nmol} / \mathrm{min})$ and angiotensin II $(5,10,20 \mathrm{pmol} / \mathrm{min})$ for two minutes at each dose with simultaneous infusion of saline at 0.1 $\mathrm{ml} / \mathrm{min}$. Forearm blood flow reached a steady state by one minute after starting infusion of drugs at each infusion rate. Infusion of these two drugs was 
alternated, and infusion of the second drug was begun at least 15 minutes after the termination of the first drug, when forearm blood flow had returned to the baseline value. Fifteen minutes after the second drug infusion, intra-arterial insulin infusion $(0.15$ $\mathrm{mU} / \mathrm{kg} / \mathrm{min}$ ) was started and continued. We confirmed previously that infusion of this dose of insulin does not alter the level of either blood glucose or serum insulin in the contralateral antecubital vein (26). After insulin infusion for 20 minutes, baseline variables were measured. While insulin was being infused, intra-arterial infusion of phenylephrine or angiotensin II was performed in the same way as before insulin infusion. Infusions of phenylephrine and angiotensin II were alternated. All drug infusions were finished within 1 hour after insulin administration was started. Forearm blood flow was recorded continuously during drug infusion. The concentration of all drugs was adjusted so that the infusion volume did not exceed $0.6 \mathrm{ml} / \mathrm{min}$. We had confirmed that the volume of infusion itself did not alter forearm blood flow (26). The last 1-minute measurements of forearm blood flow during infusion of each dose of drug were used for subsequent analysis.

\section{Measurement of Plasma Insulin and Blood Glucose Levels}

Five milliliters of blood was drawn for measurement of plasma insulin level and blood glucose level from the venous cannula of the ipsilateral arm during saline infusion and during intra-arterial infusion of insulin before simultaneous infusion with phenylephrine or angiotensin II. Blood was centrifuged immediately and stored in a freezer. Plasma insulin level was measured by radioimmunoassay at a commercial laboratory (SRL, Tokyo, Japan). Blood glucose level was measured by the glucose oxidase method.

\section{Preparation of Drugs}

Insulin (Insulin Actrapid Human; Novo Nordisk A/S, Dagsvaerd, Demmark) was diluted in saline containing $1 \%$ serum albumin and a $10-\mathrm{ml}$ sample of stock solution containing $0.1 \mathrm{U} / \mathrm{ml}$ of insulin was made by the pharmaceutical department of our hospital. Angiotensin II (Hypertensin CIBA; CibaGeigy, Basel, Switzerland) was dissolved in saline at a concentration of $100 \mathrm{nmol} / \mathrm{l}$ and $10-\mathrm{ml}$ stock solutions were made as well. Phenylephrine (Neosynesin Kowa; Kowa, Nagoya, Japan) was diluted in saline at a concentration of $10 \mu \mathrm{mol} / 1$ immediately before use.

\section{Statistical Analysis}

One-way analysis of variance (ANOVA) was used to compare baseline hemodynamic values, plasma insulin, and blood glucose levels before and during insulin infusion. The changes in forearm blood flow and forearm vascular resistance in response to phenylephrine and angiotensin II were examined by one-way ANOVA. The changes in forearm blood flow and forearm vascular resistance in response to phenylephrine and angiotensin II infusion during in-
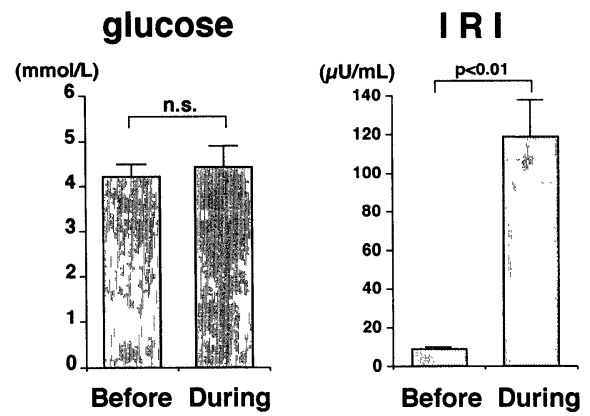

Fig. 1. Bar graphs show blood glucose levels (left panel) and serum concentrations of immunoreactive insulin (IRI) (right panel) in the ipsilateral antecubital vein before and during insulin infusion $(0.15 \mathrm{mU} / \mathrm{kg} / \mathrm{min})$. Although the levels of IRI increased significantly during insulin infusion, blood glucose levels did not change. Means \pm SEM.

sulin infusion were compared with those during saline infusion (control) by two-way ANOVA. The percent changes in forearm blood flow and forearm vascular resistance in response to vasoconstrictors were also calculated. All values are expressed as means \pm SEM. Duncan's multiple comparison test was applied when ANOVA showed significant differences, and a value of $p<0.05$ was considered to indicate statistical significance.

\section{Results}

\section{Effects of Insulin on Baseline Hemodynamics}

Insulin infusion at $0.15 \mathrm{mU} / \mathrm{kg} / \mathrm{min}$ raised the insulin level of the venous effluents of the ipsilateral arm significantly $(p<0.01)$ without changes in glucose levels in the venous effluents (Fig. 1). Insulin infusion had no overall effect on arterial pressure, baseline forearm blood flow, and forearm vascular resistance. However, in two patients, insulin infusion increased forearm blood flow (Table 2). Heart rate was not altered by insulin infusion (data not shown).

\section{Effects of Insulin on Vasoconstriction Induced by} Phenylephrine and Angiotensin II

Figure 2 shows representative plethysmographic recordings of forearm blood flow in a subject in response to intra-arterial infusion of angiotensin II at graded doses before and during simultaneous infusion of insulin at a rate of $0.15 \mathrm{mU} / \mathrm{kg} / \mathrm{min}$. Angiotensin II infusion decreased forearm blood flow dose-dependently before and during insulin infusion. Table 3 shows hemodynamic changes in response to phenylephrine and angiotensin II. Forearm blood flow decreased and vascular resistance increased in response to these vasoconstrictors during insulin infusion as well as during saline infusion. These changes were similar, and there was no significant difference between before and during insulin infusion. These drugs did not alter arterial pressure. Figure 3 shows the changes in forearm vascular resistance evoked by phenylephrine and angiotensin 
Table 2. Baseline Forearm Hemodynamics Before and During Insulin Infusion

\begin{tabular}{|c|c|c|c|c|c|c|c|c|c|c|c|c|}
\hline \multirow{3}{*}{ Patients } & \multicolumn{6}{|c|}{ Before Phenylephrine } & \multicolumn{6}{|c|}{ Before Angiotensin II } \\
\hline & \multicolumn{2}{|c|}{ FBF } & \multicolumn{2}{|c|}{$\mathrm{BP}$} & \multicolumn{2}{|c|}{ FVR } & \multicolumn{2}{|c|}{ FBF } & \multicolumn{2}{|c|}{ BP } & \multicolumn{2}{|c|}{ FVR } \\
\hline & Before & During & Before & During & Before & During & Before & During & Before & During & Before & During \\
\hline W.J & 5.44 & 5.31 & $178 / 126$ & $178 / 128$ & 26.3 & 27.2 & 4.83 & 5.46 & $180 / 126$ & $176 / 125$ & 29.8 & 26.0 \\
\hline I. Y & 3.06 & 7.44 & $152 / 96$ & $148 / 98$ & 37.5 & 15.4 & 2.41 & 3.27 & $144 / 96$ & $142 / 98$ & 46.5 & 34.5 \\
\hline M.Y & 3.07 & 2.50 & $166 / 110$ & $164 / 110$ & 41.9 & 51.2 & 3.45 & 2.79 & $170 / 112$ & $162 / 110$ & 38.0 & 45.6 \\
\hline H.K & 3.96 & 3.55 & $148 / 92$ & $138 / 90$ & 28.0 & 29.8 & 3.68 & 5.30 & $146 / 92$ & $142 / 96$ & 29.8 & 21.0 \\
\hline E.K & 2.20 & 3.11 & $160 / 100$ & $172 / 110$ & 54.4 & 42.1 & 1.96 & 1.83 & $170 / 108$ & $162 / 106$ & 65.7 & 68.2 \\
\hline T.F & 2.58 & 2.33 & $162 / 98$ & $156 / 100$ & 46.2 & 50.9 & 2.83 & 3.15 & $164 / 106$ & $158 / 102$ & 44.4 & 38.3 \\
\hline M.T & 5.76 & 7.20 & $136 / 78$ & $138 / 86$ & 16.9 & 14.3 & 6.53 & 7.13 & $148 / 80$ & $138 / 82$ & 15.7 & 14.1 \\
\hline
\end{tabular}

FBF, forearm blood flow (ml/min/100 $\mathrm{ml}$ ); BP, blood pressure ( $\mathrm{mmHg}$ ); FVR, forearm vascular resistance (units).

Table 3. Forearm Hemodynamics Before and During Insulin Infusion

\begin{tabular}{|c|c|c|c|c|c|c|c|c|c|}
\hline & & \multirow[b]{2}{*}{ Control } & \multicolumn{3}{|c|}{ Phenylephrine $(\mathrm{nmol} / \mathrm{min})$} & \multirow[b]{2}{*}{ Control } & \multicolumn{3}{|c|}{ Angiotensin II (pmol/min) } \\
\hline & & & 1 & 4 & 12 & & 5 & 10 & 20 \\
\hline \multirow{2}{*}{ MBP } & Before & $119 \pm 5$ & $118 \pm 5$ & $120 \pm 5$ & $119 \pm 5$ & $122 \pm 5$ & $121 \pm 5$ & $120 \pm 6$ & $121 \pm 6$ \\
\hline & During & $121 \pm 6$ & $120 \pm 6$ & $122 \pm 6$ & $123 \pm 6$ & $120 \pm 5$ & $121 \pm 6$ & $121 \pm 6$ & $123 \pm 5$ \\
\hline \multirow[t]{2}{*}{ FBF } & Before & $3.7 \pm 0.5$ & $3.3 \pm 0.4$ & $3.2 \pm 0.4$ & $2.5 \pm 0.3$ & $3.7 \pm 0.6$ & $2.8 \pm 0.3$ & $2.7 \pm 0.3$ & $2.4 \pm 0.2$ \\
\hline & During & $4.5 \pm 0.8$ & $3.7 \pm 0.7$ & $3.5 \pm 0.6$ & $2.7 \pm 0.3$ & $4.1 \pm 0.7$ & $3.6 \pm 0.6$ & $3.3 \pm 0.5$ & $2.9 \pm 0.3$ \\
\hline \multirow[t]{2}{*}{ FVR } & Before & $35.9 \pm 4.9$ & $38.5 \pm 4.3$ & $41.5 \pm 5.4$ & $51.3 \pm 6.2$ & $38.6 \pm 6.0$ & $45.9 \pm 5.6$ & $49.0 \pm 6.5$ & $53.4 \pm 5.7$ \\
\hline & During & $33.0 \pm 5.9$ & $38.2 \pm 5.9$ & $39.7 \pm 5.3$ & $50.3 \pm 6.9$ & $35.4 \pm 6.8$ & $40.0 \pm 7.7$ & $42.4 \pm 7.0$ & $47.1 \pm 6.7$ \\
\hline
\end{tabular}

MBP, mean blood presure ( $\mathrm{mmHg}$ ); FBF, forearm blood flow ( $\mathrm{ml} / \mathrm{min} / 100 \mathrm{ml})$; FVR, forearm vascular resistance (units).

Case ( W.J. 32yo )
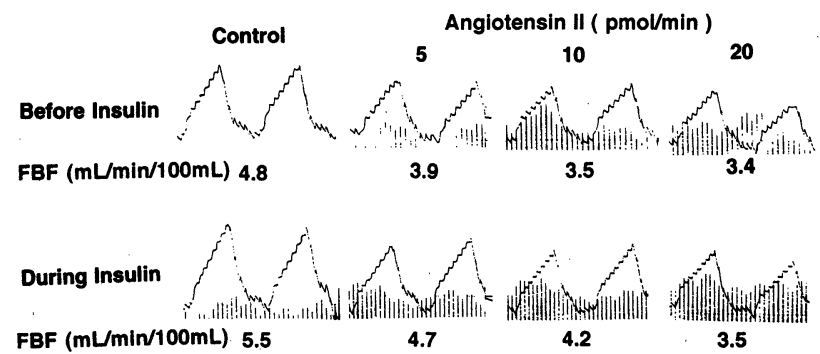

Fig. 2. These figures show representative plethysmographic recordings of forearm blood flow in a subject (W.J.) in response to intra-arterial infusion of angiotensin II at graded doses before (upper figures) and during (lower figures) simultaneous infusion of insulin at a rate of 0.15 mU $/ \mathrm{kg}$ per minute. Angiotensin II decreased forearm blood flow dose-dependently during insulin infusion, as well as in the control state during saline infusion. FBF, forearm blood flow.

II. In this study, the baseline values of forearm blood flow and forearm vascular resistance slightly varied in each subject. The duration of insulin infusion was only $20 \mathrm{~min}$ before an infusion of the first vasoconstrictor (phenylephrine or angiotensin II); therefore, insulin may have dilated forearm vessels before infusion of the second vasoconstrictor. To eliminate the effects of the variations in baseline values, we also analyzed normalized values, regarding the control value as $100 \%$. The percent changes
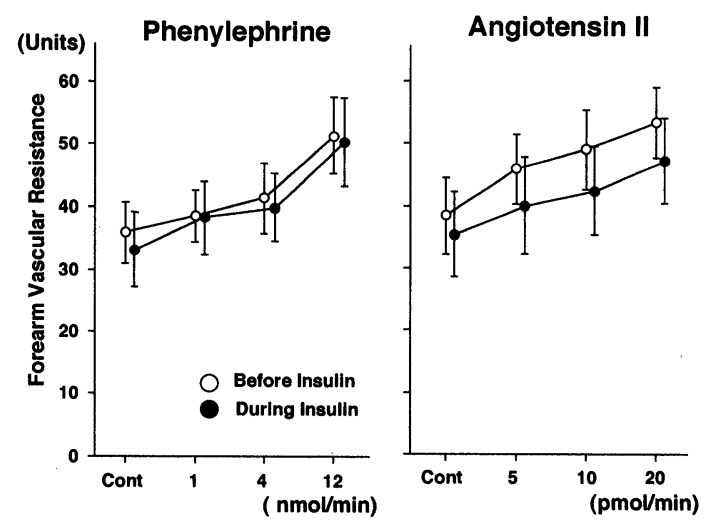

Fig. 3. Line graphs show changes in forearm vascular resistance evoked by intra-arterial infusion of graded doses of phenylephrine (left panel) and of angiotensin II (right panel). Both phenylephrine and angiotensin II increased forearm vascular resistance dose-dependently during intraarterial infusion of insulin, as well as before insulin infusion. Cont, control. Means $\pm S E M$.

in forearm vascular resistance evoked by both phenylephrine and angiotensin II were similar before and during insulin infusion (Fig. 4).

\section{Discussion}

The major finding of the present study was that hyperinsulinemia did not attenuate vasoconstrictive responses to phenylephrine and angiotensin II in 


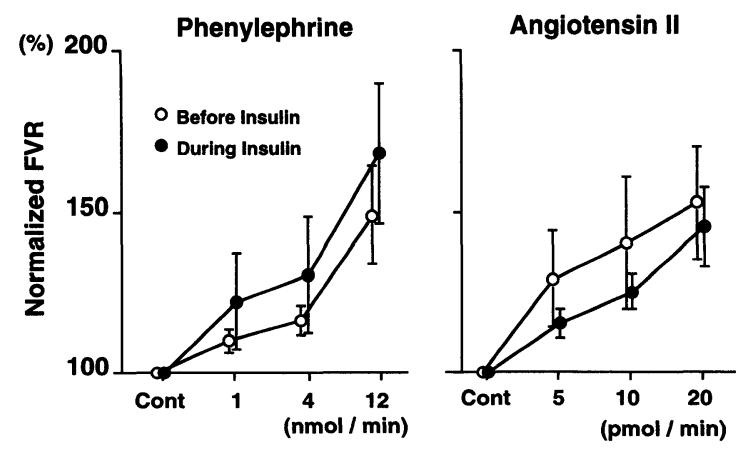

Fig. 4. Line graphs show percent changes in forearm vascular resistance evoked by intra-arterial infusion of graded doses of phenylephrine (left panel) and of angiotensin II (right panel). Both phenylephrine and angiotensin II increased forearm vascular resistance similarly and dosedependently during intra-arterial infusion of insulin and before infusion of insulin. Control value was 100\%. FVR, forearm vascular resistance; Cont, control. Means $\pm S E M$.

hypertensive humans, which differs from our previous results in normal subjects (26). It is still not clear whether insulin resistance or hyperinsulinemia causes hypertension $(32,33)$; however, the results of this study may provide one explanation as to how hyperinsulinemia contributes to hypertension. Although the vasoconstriction due to hyperinsulinemia-induced sympathetic activation is offset by the peripheral effects of insulin on vasoreactivity in normotensive humans $(20,21)$, the peripheral anti-vasoconstrictive effects of insulin may be lost in hypertensive patients, resulting in vasoconstriction in response to pressor stimuli.

\section{Effects of Insulin on Resting Forearm Vascular Resistance}

Because systemic insulin infusion may alter forearm vascular resistance via sympathetic activation, we infused insulin locally into the brachial artery. This infusion of insulin caused physiological hyperinsulinemia, approximately $120 \mu \mathrm{U} / \mathrm{ml}$, in the ipsilateral antecubital veins. This level of local hyperinsulinemia slightly increased the baseline forearm blood flow, but the increase was not statistically significant. Although we did not measure systemic insulin levels in this study, the insulin level in the contralateral arm was $11.0 \pm 0.8 \mu \mathrm{U} / \mathrm{ml}$, measured using the same methodology, in our previous study (26). Furthermore, neither blood pressure nor heart rate was altered during insulin infusion in the present study. Thus, systemic effects of insulin were excluded.

The present finding of minimal effects of insulin on baseline forearm vascular resistance in hypertensive patients is similar to that in normotensive humans. We and others have shown in normotensive humans that local hyperinsulinemia induced by intra-arterially infused insulin does not alter or slightly increases peripheral blood flow $(5,20,26$, 34-36). In hypertensive humans, Lembo et al. (15) and Neahring et al. (37) reported that local hyperinsulinemia induced by intra-arterial infusion of insulin increased forearm blood flow. We failed to observe significant changes in forearm blood flow in response to intra-arterially infused insulin in the present study. We and previous investigators (15, 37) raised the local plasma insulin to comparable levels (approximately 60-120 $\mu \mathrm{U} / \mathrm{ml}$ ); therefore, the difference between the present results and those of previous studies was not caused by different insulin levels. One possible cause for the different results is that the duration of insulin infusion was shorter in the present study $(20 \mathrm{~min})$ than in the previous studies $(>60 \mathrm{~min})(37)$. Another possibility is that our patients were much younger (mean, $26 \mathrm{yr}$ ) than those of the two previous studies (mean, 36 and 39 yr).

\section{Effects of Insulin on Vascular Reactivity to Pressor Agents in Hypertensive Subjects}

Recently, we (26) and Lembo et al. (27) reported that local hyperinsulinemia induced by intra-arterial infusion of insulin blunted the responses to vasoconstrictive stimuli in young normotensive subjects. In this study, we determined effects of intra-arterially infused insulin on vasoreactivity in young patients with hypertension. In contrast to normotensive humans, intra-arterially infused insulin did not attenuate vasoconstrictive responses to pressor agents in the patients with hypertension. Because the control values of forearm vascular resistance varied in each subject, we analyzed not only absolute values but also normalized values, regarding the control value to be $100 \%$. The percent changes in forearm vascular resistance evoked by both phenylephrine and angiotensin II were similar before and during insulin infusion.

Several possibilities were considered to explain the different effects of insulin between normotensive and hypertensive subjects. First, the difference was not due to the difference in the plasma insulin level, because in both studies insulin levels rose similarly to approximately $120-130 \mu \mathrm{U} / \mathrm{ml}$. Second, the difference is not likely due to structural changes of vessels. Although we did not directly estimate structural changes, the maximum values of forearm vascular resistance evoked by phenylephrine and angiotensin II without insulin infusion were similar in the normotensive subjects in our previous study (26) and the hypertensive patients in the present study. Third, the difference may have resulted from endothelial dysfunction in patients with hypertension. A recent report suggests that insulin may release nitric oxide from the endothelium in humans (38). Because of endothelial dysfunction in patients with hypertension (39-42), the effects of insulin on the release of nitric oxide may be impaired, resulting in loss of the anti-vasoconstrictive activity of insulin. Fourth, the presence of circulating ouabain-like substance may be implicated in the etiology of essential hypertension in humans (43, 44). Insulin may cause vasodilation by activating the $\mathrm{Na}^{+}-\mathrm{K}^{+}$ATPase activity of vascular smooth muscle $(25,43,44)$. Increased circulating levels of ouabain- 
like substance may inhibit the action of insulin in patients with essential hypertension. This possibility should be explored. Finally, many of our hypertensive patients were insulin-resistant. Although we did not study insulin-resistance by the euglycemic clamp method, five of our seven patients showed high levels of plasma insulin in 75gOGTT. It was reported that hypertensive patients have resistance to insulin-induced increases in skeletal muscle blood flow (8), indicating that effects of insulin on vascular resistance are attenuated. Although the underlying mechanism responsible for this resistance remains to be elucidated (8), the same mechanism may be responsible for the resistance to the insulin-induced attenuation of vasoreactivity. Thus, an insulin level of $120 \mu \mathrm{U} / \mathrm{ml}$ was effective in attenuating vasoreactivity in normotensive healthy subjects in our previous study (26), but may have not been sufficient to produce this effect in patients with hypertension and insulin-resistance. If we had infused larger doses of insulin, we may have observed anti-vasoconstricting effects of insulin in patients with hypertension. The mechanisms responsible for attenuating the effects of insulin on vasoreactivity cannot be explained solely on the basis of insulin-resistance, because two hypertensive patients without insulinresistance showed similar results to those in the insulin-resistant patients.

\section{Clinical Implications}

It is controversial whether hyperinsulinemia contributes to hypertension $(32,33)$. Acute systemic hyperinsulinemia activates sympathetic nerve activity but does not raise blood pressure in normotensive humans by its anti-pressor effects on the peripheral blood vessels (18). Our study suggests that hyperinsulinemia may contribute to hypertension in patients with hypertension because the antipressor effects of insulin are lost.

Anderson et al. (45) and Lembo et al. (15) reported that systemic hyperinsulinemia produced by an euglycemic glucose clamp method did not raise arterial pressure in hypertensive subjects. However, plasma insulin concentrations in their studies $(73 \pm 7$ and $56 \pm 7 \mu \mathrm{U} / \mathrm{ml}$, respectively) were relatively low. It is possible that higher concentrations of plasma insulin may have raised arterial pressure in their studies.

If loss of the anti-vasoconstrictive effects of insulin is due to insulin resistance, hyperinsulinemia may contribute to the development of hypertension in subjects who have insulin resistance, such as obese subjects or patients with diabetes mellitus. It should be borne in mind that antihypertensive drugs that cause insulin resistance may attenuate the antivasoconstrictive effects of insulin.

In summary, the present study demonstrated that the anti-vasoconstrictive effects of insulin on the peripheral vessels are lost in patients with hypertension. Hyperinsulinemia may contribute to the development and maintenance of hypertension not only in patients with hypertension, but also in any subject with insulin-resistance. In these latter subjects, the balance between the pressor and depres- sor effects of insulin may be altered in favor of its pressor effects.

\section{Acknowledgment}

This study was supported by Research Grants for Cardiovascular Disease (3C-5) from the Ministry of Health and of Welfare. We appreciate Drs. Daisuke Teshima and Osamu Fujishita from the pharmacological section for preparing the drugs used in this study.

\section{References}

1. Ferrannini E, Buzzigoli G, Bonadonna R, et al: Insulin resistance in essential hypertension. $N$ Engl $J$ Med 1987; 317: 350-357.

2. Lucas CP, Estingarribia JA, Darga LL, Reaven GM: Insulin and blood pressure. Hypertension 1985; 7: 702-706.

3. Modan M, Halkin H, Almog S, Lusky A, Eshkol A, Shefi M: Hyperinsulinemia: a link between hypertension obesity and glucose intolerance. $J$ Clin Invest 1985; 75: 809-817.

4. Capaldo B, Lembo G, Napoli R, et al.: Skeletal muscle is a primary site of insulin resistance in essential hypertension. Metabolism 1991; 40: 1320-1322.

5. Ferrannini E, Galvan AQ: Hyperinsulinemia, insulin resistance, and blood pressure. Hypertens Res 1992; 15: $67-75$.

6. Landin K, Tengborn L, Smith U: Treating insulin resistance in hypertension with metformin reduces both blood pressure and metabolic risk factors. J Intern Med 1991; 229: 181-187.

7. Pershadsingh HA, Kurtz TW: Pharmacologic reversal of hyperinsulinemia is associated with a reduction in blood pressure: a novel approach to treatment of hypertension. Hypertension 1992; 20: 410 (abstr).

8. Baron AD, Brechtel-Hook G, Johnson A, Hardin D: Skeletal muscle blood flow. A possible link between insulin resistance and blood pressure. Hypertension 1993; 21: 129-135.

9. Brands MW, Hildebrandt DA, Mizelle HL, Hall JE: Sustained hyperinsulinemia increases arterial pressue in concious rats. Am J Physiol 1991; 260: R764R768.

10. Berne C, Fagius J, Pollare T, Hjemdahl P: The sympathetic response to euglycaemic hyperinsulinaemia. Evidence from microelectrode nerve recordings in healthy subjects. Diabetologia 1992; 35: 873-879.

11. DeFronzo RA, Cooke CR, Anders R, Faloona GR, Davis PJ: The effect of insulin on renal handling of sodium, potassium, calcium and phosphate in man. $J$ Clin Invest 1975; 55: 845-855.

12. Feldoman RD, Bierbrier GS: Insulin-mediated vasodilation; impairment with increased blood pressure and body mass. Lancet 1993; 342: 707-709.

13. Gans ROB, Toorn L, Bilo HJG, Nauta JJP, Heine RJ, Donker AJM: Renal and cardiovascular effects of exogeneous insulin in healthy volunteers. Clin Sci 1991; 80: 219-225.

14. Gesek FA, Schoolwerth AC: Insulin increases $\mathrm{Na}^{+}$. $\mathrm{H}^{+}$exchange activity in proximal tubules from normotensive and hypertensive rats. Am J Physiol 1991; 260: F695-F703.

15. Lembo G, Napoli R, Capaldo B, et al: Abnormal sympathetic overactivity evoked by insulin in the skeletal muscle of patients with essential hypertension. J Clin Invest 1992; 90: 24-29.

16. Reikeras O, Gunners P: Effects of high doses of in- 
sulin on systemic haemodynamics and regional blood flows in dogs. Clin Physiol 1986; 6: 129-138.

17. Rowe JW, Young JB, Minaker KL, Stevens AL, Pallotta J, Landsberg L: Effect of insulin and glucose infusions on sympathetic nerveous system activity in normal man. Diabetes 1981; 30: 219-225.

18. Anderson EA, Hoffman RP, Balon TW, Sinkey CA, Mark AL: Hyperinsulinemia preduces both sympathetic neural activation and vasodilation in normal humans. J Clin Invest 1991; 87: 2246-2252.

19. Liang CS, Doherty JU, Faillace R, et al: Insulin infusion in concious dogs. J Clin Invest 1982; 69: 1321-1336.

20. Creager MA, Liang CS, Coffman JD: Beta adrenergic-mediated vasodilator response to insulin in the human forearm. J Pharmacol Exp Ther 1985; 235: 709-714.

21. Laakso M, Edelman SV, Brechtel EG, Baron AD: Decreased effects of insulin to stimulate skeletal muscle blood flow in obese man. J Clin Invest 1990; 85: 1844-1852.

22. Yagi S, Takata S, Kiyokawa $\mathrm{H}$, et al: Effects of insulin on vasoconstrictive responses to norepinephrine and angiotensin II in rabbit femoral artery and vein. Diabetes 1988; 37: 1064-1067.

23. Bhagat B, Burke WJ, Dhalla NS: Insulin-induced enhancement of uptake of noradrenaline in atrial strips. Br J Pharmacol 1981; 74: 325-332.

24. Standley PR: Insulin attenuates vasopressin-induced calcium transient and voltage-dependent calcium response in rat vascular smooth muscle cells. $J$ Clin Invest 1991; 88: 1230-1236.

25. Kahn AM, Seidel CL, Allen JC, O'Neil RG, Shelat $\mathrm{H}$, Song $\mathrm{T}$ : Insulin reduces contraction and intracellular calcium concentration in vascular smooth muscle. Hypertension 1993; 22: 735-742.

26. Sakai K, Imaizumi $\mathrm{T}$, Masaki H, Takeshita A: Intraarterial infusion of insulin attenuates vasoreactivity in human forearm. Hypertension 1993; 22: 67-73.

27. Lembo $G$, Rendina $V$, Iaccarino $G$, Lamenza $F$, Volpe M, Trimarco B: Insulin reduces reflex forearm sympathetic vasoconstriction in healthy humans. Hypertension 1993; 21: 1015-1019.

28. Natali A, Santoro D, Palombo C, Cerri M, Ghione S, Ferrannini E: Impaired insulin action on skeletal muscle metabolism in essential hypertension. Hypertension 1991; 17: 170-178.

29. Omori S, Ueda K, Kiyohara Y, Kato I, Ohmura T, Fujishima M: Relation between insulin and blood pressure in a Japanese general population: The Hisayama study. J Hypertens 1992; 10(suppl 4): S140 (abstr).

30. Imaizumi $T$, Takeshita $A$, Ashihara $T$, Nakamura $M$ : The effects of sublingually administered nitroglycerin on forearm vascular resistance in patients with heart failure and in normal subjects. Circulation 1985; 72:
747-752.

31. Imaizumi $\mathrm{T}$, Hirooka $\mathrm{Y}$, Masaki $\mathrm{H}$, et al: Effects of $\mathrm{L}$-arginine on forearm vessels and responses to acetylcholine. Hypertension 1992; 20: 511-517.

32. Anderson EA, Mark AL: The vasodilator action of insulin. Implications for the insulin hypothesis of hypertension. Hypertension 1993; 21: 136-141.

33. Hall JE, Coleman TG, Mizelle HL: Does chronic hyperinsulinemia cause hypertension? Am J Hypertens 1989; 2: 171-173.

34. Natali A, Buzzigoli G, Taddei S, et al: Effects of insulin on hemodynamics and metabolism in human forearm. Diabetes 1990; 39: 490-500.

35. Gelfand RA, Barrett EJ: Effect of physiologic hyperinsulinemia on skeletal muscle protein synthesis and breakdown in man. $J$ Clin Invest 1987; 80: 1-6.

36. Jamerson KA, Julius S, Gudbrandsson T, Anderson $\mathrm{O}$, Brant $\mathrm{O}$ : Reflex sympathetic activation induces acute insulin resistance in the human forearm. Hypertension 1993; 21: 618-623.

37. Neahring JM, Stepniakowski K, Greene AS, Egan $\mathrm{BM}$ : Insulin does not reduce forearm $\alpha$-vasoreactivity in obese hypertensive or lean normotensive men. Hypertension 1993; 22: 584-590.

38. Steinberg $\mathrm{HO}$, Brechtel $\mathrm{G}$, Johnson A, Baron AD: Insulin modulates endothelium derived relaxing foctor/nitric oxide dependent vasodilation in skeletal muscle. Hypertension 1993; 22: 436 (abstr).

39. Koga T, Takata Y, Kobayashi K, Takishita S, Yamashita Y, Fujishima M: Age and hypertension promote endothelium-dependent contractions to acetylcholine in the aorta of the rat. Hypertension 1989; 14: 542-548.

40. Fujii K, Tominaga M, Ohomori S, et al: Decreased endothelium-dependent hyperpolarization to acethylcholine in smooth muscle of the mesenteric artery of spontaneously hypertensive rats. Circ Res 1992; 70: 660-669.

41. Mayhan WG, Faraci FM, Heistad DD: Impairment of endothelium-dependent responses of cerebral arterioles in chronic hypertension. Am J Physiol 1987; 253: H1435-H1440.

42. Mayhan WG: Impairment of endothelium-dependent dilatation of basilar artery during chronic hypertension. Am J Physiol 1990; 259: H1455-H1462.

43. Hamlyn JM, Ringel R, Schaeffer J, et al: A circulating inhibitor of $\mathrm{NA}^{+} \mathrm{K}^{+}$ATPase associated with essential hypertension. Nature 1982; 300: 650-653.

44. deWardener HE: Kidney, salt intake and $\mathrm{Na}^{+}, \mathrm{K}^{+}$. ATPase inhibitors in hypertension. Hypertension 1990; 17: 830-836.

45. Anderson EA, Balon TW, Hoffman RP, Sinkey CA, Mark AL: Insulin increases sympathetic activity but not blood pressure in borderline hypertensive humans. Hypertension 1992; 19: 621-627. 